Filozofska fakulteta, Univerza v Ljubljani

DOI: 10.4312/vestnik.10.169-186

cvetka.sokolov@ff.uni-lj.si

\title{
ANALIZA ZGLEDOV MERIL ZA RAZČLENJEVALNO OCENJEVANJE RAZLAGALNIH IN UTEMELJEVALNIH PISNIH SESTAVKOV
}

UVOD

Strokovna literatura na temo razčlenjevalnega ocenjevanja pisnih sestavkov ponuja različna merila. Njihova analiza razkriva različne poglede na dejavnike, ki so sestavni del kakovostnega pisanja: strokovnjaki in strokovnjakinje s področja testiranja, avtorji in avtorice kriterijev, pripisujejo določenim sestavinam besedila večjo težo kot drugim, kar se odraža tako v njihovi izbiri vidikov, ki jih vključijo v merila, kakor tudi v deležu, ki ga pri končni oceni odmerijo določnemu vidiku. Natančnejša razčlemba meril razkrije tudi razlike $\mathrm{v}$ terminologiji, različne poglede na klasifikacijo besedilnih prvin, občasno pa tudi pomanjkanje jezikoslovnega ali/in besediloslovnega znanja. Merila se med seboj razlikujejo tako po številu ravni kakor tudi po številu kategorij, ki se vrednotijo.

V članku sta predstavljena in kritično ovrednotena dva zgleda razčlenjevalnih meril za ocenjevanje razlagalnih/utemeljevalnih sestavkov, in sicer Meril Holly L. Jacobs et al. (1981) in Navodil za ocenjevanje ${ }^{1}$ Vicki Spandlove et al. (1990). Članek se osredotoča na dobre plati in hkrati opozarja na tako ali drugače sporne opisnike v obravnavanih merilih. Iz analize je razvidno, da merila niso vedno neproblematična, čeprav jih poiščemo v strokovni literaturi; zato jih je pred uporabo potrebno kritično ovrednotiti in po potrebi izboljšati oziroma prilagoditi konkretnemu izobraževalnemu kontekstu.

\section{LASTNOSTI KAKOVOSTNIH OPISNIKOV}

Pri razčlembi in vrednotenju izbranih meril se bomo osredotočili na štiri lastnosti, ki jih priporoča Splošni evropski jezikovni okvir/SEJO (2001: 205-207; v nadaljevanju Okvir): dorečenost, jasnost, kratkost in neodvisnost.

Dorečenost označuje izogibanje nekonkretnim in meglenim formulacijam, kot npr. »posamezni izvirni vpogledi $\ll^{2}$ in $»$ nalogi primerno besedišče $\ll^{3}$, če zgleda vzamem kar iz

1 Scoring Guide

2 »some original insights «

3 "vocabulary appropriate to task « 
meril, ki jih lektorice uporabljamo na Oddelku za anglistiko in amerikanistiko Filozofske fakultete Univerze v Ljubljani (2014). Kakšni »vpogledi« so pravzaprav »izvirni« in kaj je »primerno besedišče«? Ker pa se nedorečenosti v celoti ni mogoče izogniti, če naj bodo merila dovolj splošna, da bodo uporabna za raznolike pisne sestavke znotraj različnih besedilnih zvrsti, naletimo na zglede podobno nekonkretnih opisnikov tudi $\mathrm{v}$ Okviru, na primer v preglednici C4, ki pokriva »Mrežo opisnikov za ocenjevanje pisne zmožnosti« (C1: Razpon) $)^{4}$ : »Slog in ton pisanja sta do neke mere neprožna « ${ }^{5}$ (Priročnik 2009: 187; moj poudarek) Pri ocenjevanju pisnih sestavkov je zato ključnega pomena standardizacija ocenjevanja - usklajevanje razumevanja opisnikov s strani ocenjevalcev in ocenjevalk na podlagi testnih primerkov izpitnih izdelkov.

Nedorečeni opisniki so tudi tisti, pri katerih sestavljalci/sestavljalke meril razlike med njimi s 'kozmetičnimi' posegi in minimalnimi preubeseditvami ustvarijo umetno.

Razlike med posameznimi stopnjami na lestvici ne smejo biti odvisne od nadomeščanja določiteljev, kot na primer "nekaj" ali "nekateri" z "mnogo" ali "večina", ali z nadomeščanjem "precej široko" z "zelo široko" ali "poprečno" z "dobro" na višji stopnji. Razlike med opisniki ne smejo biti samo črke na papirju. To lahko pomeni, da bodo na ocenjevalni lestvici vrzeli na mestih, kjer ni mogoče uvesti opisnikov, ki bi se drug od drugega razlikovali dejansko in dovolj očitno. ${ }^{6}$ (Svet Evrope 2001: 206)

Zahteva po jasnosti se nanaša na izogibanje pretirano zapleteni strokovni terminologiji in na preprosto, nazorno in logično ubeseditev opisnikov; jasni opisniki so nedvoumni, česar pa ne moremo trditi niti za vse opisnike v Okviru - Spiros Papageorgiou (2009:

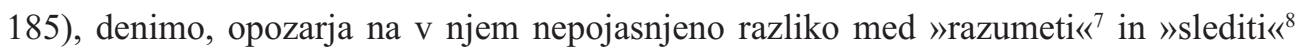
(oziroma njeno odsotnost): »Ni jasno, ali sta dva različna glagola (v zgornjem primeru 'razumeti' in 'slediti') uporabljena kot sinonima ali označujeta dva različna procesa. «9

Naslednja zaželena lastnost opisnikov, njihova kratkost, prispeva k preglednosti in omogoča lažjo in bolj zanesljivo/dosledno uporabo meril. »Opisnik, ki je daljši od dvostavčne povedi, ocenjevalcu ali ocenjevalki v resnici ni v pomoč. «10 (Svet Evrope 2001: 207) Krajši in konkretni opisniki so pogoj za njihovo neodvisnost, kar pomeni, da

4 »Written Assessment Criteria Grid« (C1: Range)

5 »The flexibility in style and tone is somewhat limited."

6 Distinctions between steps on a scale should not be dependent on replacing a qualifier like 'some' or 'a few' with 'many' or 'most' or by replacing 'fairly broad' with 'very broad' or 'moderate' with 'good' at the next level up. Distinctions should be real, not word-processed and this may mean gaps where meaningful, concrete distinctions cannot be made. (Council of Europe 2001: 206)

7 »understand «

8 »follow «

$9 »[\mathrm{I}] \mathrm{t}$ is not clear whether different verbs (in the above example 'understand' and 'follow') are used as synonyms or indicate different processes."

10 »A descriptor which is longer than a two-clause sentence cannot realistically be referred to during the assessment process.« 
jih je mogoče uporabiti kot $»$ neodvisne kriterijske trditve $\ll^{11}$, denimo na kontrolnih seznamih. »Tovrstna neodvisnost nakazuje, da ima opisnik sam po sebi oprijemljiv pomen, katerega interpretacija ni odvisna od njegove primerjave $\mathrm{z}$ ubeseditvijo drugih opisnikov na lestvici. « ${ }^{12}$ (Svet Evrope 2001: 207)

3 SPORNI OPISNIKI

Sporni opisniki niso v skladu z zgoraj navedenimi priporočili Okvira. Za potrebe pričujoče analize sem jih razdelila v naslednje skupine:

Dvoumni opisniki so opisniki v določenih ocenjevanih kategorijah, ki bi jih lahko razumeli tudi kot opisnike, ki se nanašajo na katero od drugih kategorij. Da uporabniki opisnike interpretiramo različno, ni presenetljivo. Razlike v razumevanju so posledica razlik v percepciji, ki je odvisna od naših izkušenj, prepričanj, znanja in, ne nazadnje, od naše osebnosti. Za nameček je pisni sestavek kompleksna celota, ki jo v sestavne dele $\mathrm{v}$ prid večji preglednosti in boljšemu razumevanju razbijemo umetno. V resnici se $\mathrm{v}$ večji ali manjši meri pokrivajo, zato je jasna razmejitev med njimi občasno težavna. $\mathrm{V}$ tej luči je toliko bolj pomembno, da razlik v razumevanju z dvoumno razporeditvijo in/ ali ubeseditvijo ne povečujemo, temveč da poskrbimo za največjo možno mero jasnosti in preglednosti. Dvoumna razporeditev opisnikov povečuje razlike v interpretaciji meril in lahko privede do tega, da pri ocenjevanju isto lastnost besedila vrednotimo dvakrat, zaradi česar trpi zanesljivost ocenjevanja.

Neustrezno kategorizirani opisniki so opisniki, ki ne sodijo v kategorijo, v katero so razvrščeni. Tako razporejeni opisniki razkrivajo površnost ali pomanjkljivo znanje tistih, ki so se jih domislili. Poleg tega, da širijo neznanje, postavijo pod vprašaj dele konstrukta (lastnosti izdelka, ki jih v določeni kategoriji ocenjujemo).

Neustrezno poimenovani opisniki so opisniki, v katerih so strokovni termini uporabljeni neustrezno, na primer, termin »kohezija« namesto »koherenca«.

Neprimerni/Nerelevantni opisniki so opisniki, s katerimi ocenjevalec/ocenjevalka vrednoti vidike izdelka, ki niso del konstrukta, denimo, (ne)urejenost pisave.

Teoretiki testiranja (Bacha 2001: 373; Brown 2004: 243; Hughes 2003: 103; Cushing Weigle 2002: 116; Hamp-Lyons 1990: 78, Polio 2001: 102) se pogosto sklicujejo na merila, ki so jih za ocenjevanje pisnih sestavkov v angleščini kot drugem oziroma tujem jeziku leta

11 »independent criteria statements«

12 »This kind of independent integrity is a signal that the descriptor could serve as an objective rather than having meaning only relative to the formulation of other descriptors on the scale.« 
1981 razvili Holly L. Jacobs, Stephen A. Zinkgraf, Deanna R. Wormuth v Faye Hartfiel in Jane B. Hughey. To je eden od glavnih razlogov, da sem jih vključila v analizo. Drugi je povezan s prvim - ta merila so, kot ugotavlja Richard H. Haswell (2007: 2), med učitelji in učiteljicami (ne samo v ZDA, ampak v mednarodnem prostoru) zelo priljubljena in zato kljub oddaljeni letnici nastanka $-\mathrm{v}$ široki uporabi: »Navodila za ocenjevanje [Jacobs et al.)] in njihove priredbe so priljubljena od leta 1981, ko so izšla. Poznajo jih tisti, ki so jih prejeli na izročkih kot udeleženci in udeleženke izobraževalnih delavnic, in tisti, ki so naleteli na fotokopirane izvode, pozabljene v kotičkih fakultet, namenjenim pitju kave. «13

Prav ta merila sem izbrala tudi zato, ker gre za prva razčlenjevalna merila, s katerimi sem kot učiteljica prišla v stik na enem od seminarjev Novosti stroke, ki jih vsako leto organizira Oddelek za anglistiko in amerikanistiko Filozofske fakultete Univerze v Ljubljani, in ki sem jih s pridom uporabila za oblikovanje prvih razčlenjevalnih meril za ocenjevanje pisnih sestavkov pri predmetu lektorske vaje na Filozofski fakulteti Univerze v Ljubljani. Nekaj let pozneje so mi na nekem drugem seminarju spet prišla v roke. Pri predmetu jezik v rabi na Oddelku za anglistiko in amerikanistiko še danes uporabljamo merila, ki se naslanjajo tudi na merila Jacobs et al.

Avtorji meril predvidevajo ocenjevanje/točkovanje naslednjih petih vidikov pisanja: vsebine $^{14}$, zgradbe $^{15}$, besedišča ${ }^{16}$, jezikovne rabe $^{17}$ in pravopisnega nadzora ${ }^{18}$, razdeljenih na štiri ocenjevalne ravni ${ }^{19}$, in sicer (od najvišje do najnižje): odlično do zelo dobro ${ }^{20}$, dobro do povprečno ${ }^{21}$, zadovoljivo do slabo ${ }^{22}$ in zelo slabo ${ }^{23}$. Merila za doseganje določene ravni opredeljujejo opisniki, ki podrobneje pojasnjujejo, o kakovosti katerih lastnosti besedila presojamo, ko vrednotimo, na primer, vsebino izdelka. Prvine besedila, ki jih pokri-

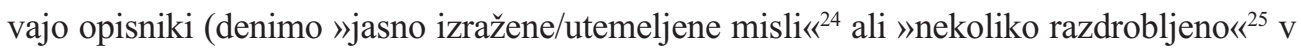
sklopu zgradbe besedila), lahko razumemo kot 'podvidike' oziroma po Haswellu ( 2007: 4) 'podznačilnosti'126 pisnega izdelka. Kriteriji določajo tudi razpon točk, znotraj katerega se ocenjevalci/ocenjevalke odločajo za število točk glede na raven, ki jo v konkretni kategoriji, recimo zgradbi, pisni izdelek dosega. Največji pomen so sestavljalci in sestavljalke meril pripisali vsebini, ki lahko kandidatu/kandidatki prinese do 30 točk, na drugem mestu

$13 »$ Since this scoring guide was published in 1981, it has proved very popular. It, or its offspring, will be familiar from workshop handouts or Xeroxes left behind in faculty coffee rooms.«

14 content

15 organization

16 vocabulary

17 language use

18 mechanics/orthographic control (CEFR 2011: 118)

19 rating levels

20 excellent to very good

21 good to average

22 fair to poor

23 very poor

24 »ideas clearly stated/supported «

25 »somewhat choppy«

26 'subtraits' 
je jezikovna raba (do 25 točk), tretje mesto si delita zgradba in besedišče (do 20 točk), medtem ko je na koncu na vrsti še kategorija pravopisni nadzor (do 5 točk).

Opisniki Jacobs et al. se nedoločenosti ne izognejo v celoti (npr. »poglobljeno besedišče/ustrezen razpon besedišča ${ }^{27}$ ), sicer pa so jasni (uporabljajo le osnovno strokovno terminologijo, poznavanje katere od študentov in študentk lahko pričakujemo, npr. »teza«, »razvoj misli«, »obvladovanje konvencij« ${ }^{28}$ ), kratki (izraženi s ključnimi beseda$\mathrm{mi}$ in ne v celih stavkih) in neodvisni od ostalih opisnikov.

Ne glede na naštete dobre plati pa analiza opisnikov meril Jacobs et al. zlasti pri vidikih zgradba in pravopisni nadzor razkrije tudi naslednje dvome in/ali pomanjkljivosti:

Zgradba: odlično do zelo dobro

Avtorji meril k zgradbi sestavka med drugim prištejejo »tekoče izražanje ${ }^{29}$. Če se opisnik nanaša na lastnost besedila, da »se gladko bere«, potem je povezava s koherenco (in s tem z zgradbo) sestavka očitna, lahko pa bi jo seveda razumeli kot gibko rabo jezika ali tekoč slog, kar, strogo vzeto, ne sodi več k presoji o kakovosti zgradbe besedila. Seveda se jezik, ki gladko teče, tudi gladko bere, kar nemara upraviči odločitev avtorjev, toda v primeru slednje interpretacije je po moji presoji vendarle v ospredju jezikovna raba. Opisnik »tekoče izražanje« me spomni na opisnike kot »tekoča raba angleščine, blizu rabi domačih govorcev « ${ }^{30}$ (Brown 2004: 245), »slovnica blizu rabi slovnice domačih govorcev « ${ }^{31}$ (Carr 2000: 236), »akademska raba besedišča in registra, blizu rabi domačih govorcev « ${ }^{32}$ (ibid.), »večina izrazov zveni idiomatsko « ${ }^{33}$ (SAR 2018: 108) in »raba frazemov se redko (če sploh) razlikuje od rabe frazemov izobraženih domačih govorcev « ${ }^{34}$ (Anderson v Harris 1968, naveden v Hughes 2003: 101), ki jih najdemo v številnih drugih ocenjevalnih lestvicah pod kategorijo »raba jezika (slovnica in besedišče) « ${ }^{35}$ (glej npr. Brown 2004: 245; Carr 2000: 236; Hughes 2003: 101; SAR 2018: 108). Tudi Charlene Polio (2001: 105) opaža, da se termin »tekoče izražanje« v merilih pogosto nanaša na »kako podobno pisanju domačih govorcev je pisanje « ${ }^{36}$. Očitno je opisnik dvoumen, zato bi ga veljalo preubesediti, na primer v »se bere tekoče«.

Pod zgradbo je na najvišji ravni (odlično do zelo dobro) v merilih Jacobs et al. naveden tudi opisnik »koheziven $\ll^{37}$. Ker se vezljivost/ kohezija ${ }^{38}$ nanaša na jezikovna sredstva,

27 »sophisticated /adequate range of vocabulary«

28 »thesis «, »development of ideas «, »mastery of conventions «

29 »fluent expression«

30 »native-like fluency in English«

31 »the grammar is native-like«

32 »the grammar is native-like«

33 »most expressions have an idiomatic feel to them «

34 »idiom rarely (if at all) distinguishable from that of educated native writer «

35 »Language use (grammar/vocabulary)«

36 »how native the writing sounds«

37 »cohesive«

38 cohesion 
ki jih uporabljamo za zagotavljanje sovisnosti/koherence (McCarthy 1991: 26; Lang 1995: izroček), in ker kohezija sama po sebi ne zagotavlja koherence (za podrobnejšo obravnavo glej npr. Enkvist 1990: 13; Sokolov 1999: 10-17; 70; Widdowson 1978: 29), ocenjujem, da je raba tega termina povsem neustrezna in da bi ga bilo potrebno nadomestiti z izrazom »koherenten « ${ }^{39}$ - ker pa ta dejansko bdi nad drugimi opisniki (»jasno izražene misli $\ll^{40}, » j$ edrnat $\ll^{41}, »$ dobro zgrajen $\ll^{42}, »$ logično zaporedje $\left.\ll^{43}\right)$, je kot opisnik pravzaprav nepotreben; bolj smiselno bi ga bilo dodati k opredelitvi kategorije zgradba besedila (kot zgradba/koherenca ali zgradba in koherenca ${ }^{44}$ ), s čimer bi kategorijo natančneje določili. Zanimivo je, da se termin »koheziven« ne ponovi na nobeni od nižjih ravni, čeprav brez koherence (ki jo zagotavljajo kohezivne vezi) ni (niti okrnjene) komunikacije.

Zgradba: dobro do povprečno in zadovoljivo do slabo

Opisnik »okrnjene utemeljitve « ${ }^{45}$ nima z zgradbo in koherenco pisnega sestavka nobene povezave; pomanjkljivo utemeljevanje/razvijanje izraženih misli se namreč navezuje na njegovo vsebino. Opisnik je torej razvrščen v zanj neustrezno kategorijo. Isto velja za del opisnika z ravni zadovoljivo do slabo: »manjkata logično zaporedje in razvoj misli ${ }^{46}$ (moj poudarek), kjer se razvoj misli prav tako nanaša na vsebino in ne na zgradbo sestavka.

\section{Pravopisni nadzor}

Pri kategoriji pravopisni nadzor zmoti, da se v njenem okviru ocenjuje tudi (ne)ustreznost členitve besedila $\mathrm{v}$ odstavke ${ }^{47}$, čeprav opisniki »malo napak pri členitvi v odstavke ${ }^{48}$, »občasne napake pri členitvi v odstavke, a ne na račun jasnosti pomena $\ll^{49}$; "pogoste napake pri členitvi v odstavke; pomen zmeden ali nejasen $\kappa^{50}$ in $»$ prevladujejo napake pri členitvi v odstavke « ${ }^{51} \mathrm{v}$ skladu s teoretičnim spoznanji o zgradbi in koherenci besedila $\mathrm{v}$ resnici sodijo v kategorijo »zgradba«. Ustrezna razporeditev odstavkov je namreč pomemben mehanizem za zagotavljanje koherence celotnega sestavka. (Glej na primer Wikborg 1990: 134 in Sokolov 1999: 101) Da bi preverila, do kakšne mere se opisniki, ki opredeljujejo pravopisni nadzor, ujemajo s siceršnjimi pristopi k tej kategoriji, sem

39 »coherent«

40 »ideas clearly stated «

41 »succinct"

42 »well-organized «

43 »logical sequencing"

44 organization/coherence, organization and coherence

45 »limited support«

46 »lacks logical sequencing and development«

47 paragraphing

48 »few errors of paragraphing "

49 »occasional errors of paragraphing but meaning not obscured«

50 »frequent errors of paragraphing; meaning confused or obscured «

51 »dominated by error of paragraphing" 
si ogledala domačo strani Oddelka za lingvistiko naključno izbrane ameriške univerze, Univerze Ohio. K pravopisnemu nadzoru prištevajo vse, kar je razvidno iz meril Jacobs et al., vključno s členitvijo v odstavke (ki jo neposredno povežejo s koherenco sestavka) plus rabo povezovalcev ${ }^{52}$ (Ohio University 2009), ki kot kohezivne vezi definitivno sodijo h kategoriji koherence (glej na primer Wikborg 1990: 134 in Sokolov 1999: 101) Raba ločil, raba velike začetnice in pravilen zapis besed ${ }^{53}$ pa so tako in tako del jezikovne rabe (prim. Polio 2001: 94).

Zanimiv 'podvidik' pravopisnega nadzora je tudi pisava/rokopis ${ }^{54}$, ki se pojavi na ravni zadovoljivo do slabo kot »neurejena pisava $\aleph^{55}$, na ravni zelo slabo pa kot »nečitljiva pisava ${ }^{56}$. Neberljivi rokopisi so seveda problem, primerljiv z besedili, ki denimo niso dovolj dolga, da bi jih lahko ovrednotili ${ }^{57}$, medtem ko je »neurejen rokopis« nadležna in zamudna lastnost besedila, »[neprijetna spremljevalka] ocenjevanja «, kot jo poimenuje Sonja Čokl (Čokl in Cankar 2008: 27), vendar branja ne onemogoča. Nekateri teoretiki pisanja upoštevanje neurejenosti rokopisa uvrščajo med vzroke za pristranskost ocenjevalcev/ ocenjevalk, medtem ko Rob Schoonen (2011: 703) opozarja na povezavo med uspešnostjo sporazumevanja in (ne)urejenostjo pisave. Kljub temu se nagiba k stališču, da rokopis kot nejezikovna prvina besedila ne more biti predmet ocenjevanja: »Neberljiv rokopis je lahko za sporočanje usoden, a intenziven jezikovni tečaj problema skoraj gotovo ne bo rešil. Večina ljudi bi se verjetno strinjala, da rokopis ni jezikovna zmožnost. « ${ }^{58}$

Če je tako, so opisniki, ki se nanašajo na pisavo, pod pogojem, da je sestavek še mogoče prebrati, neprimerni/nerelevantni.

Po merilih Jacobs et al. ima kategorija pravopisni nadzor majhno težo; poleg tega so raziskave pokazale, da je razlikovanje med kakovostjo izdelkov v tej kategoriji lahko nezanesljivo, in da za to, da pravopisni nadzor obravnavamo kot ločeno kategorijo in konstrukt, sploh ni teoretične podlage (Polio 2001: 102). Zato bi bilo opisnike pod kategorijo pravopisni nadzor smiselno premestiti v kategoriji zgradba in jezikovna raba, tiste, ki se nanašajo na (ne)čitljivost pisave, pa opustiti.

Sklepna ugotovitev analize meril Jacobsove et al. je, da so opisniki, ki jih sestavljajo, v veliki meri primerni in pri oblikovanju novih kriterijev uporabni za kombiniranje s tistimi iz drugih strokovnih virov, da pa hkrati vsebujejo sporne elemente, ki bi jih bilo potrebno izboljšati oziroma opustiti.

\footnotetext{
52 Linking/transitional devices; transitions

53 spelling

54 handwriting

55 "poor handwriting"

56 »handwriting illegible«

57 »not enough to evaluate«

58 "Illegible handwriting can be fatal to the communication of ideas but at the same time an intensive language course will most likely not solve the problem. Most people probably would agree that handwriting is not a language ability.«
} 


\section{RAZČLEMBA NAVODIL ZA OCENJEVANJE (ANGL. SCORING GUIDE) VICKI SPANDLOVE ET AL. (1990)}

Merila, ki jih vsebujejo navodila za ocenjevanje Vicki Spandlove et al. (Spandel in Stiggins 1990: 29-36), sem izbrala pod vtisom uporabniku/uporabnici prijaznega in hkrati strokovno podkovnega priročnika Vicki Spandel in Richarda Stigginsa Ustvarjanje piscev: Povezovanje ocenjevanja in poučevanja pisanja ${ }^{59}$ (1990). Kot Spandlova pojasnjuje v opombi, je merila leta 1984 pod njenim mentorstvom izdelala skupina sedemnajstih učiteljic in učiteljev, do danes pa so bila že neštetokrat preoblikovana in izpopolnjena (Spandel in Stiggins 1990: 29). Če se za njimi razgledamo po internetu, ugotovimo, da jih ameriški učitelji in učiteljice $\mathrm{v}$ več konkretnim izobraževalnim kontekstom prilagojenih različicah uporabljajo na različnih stopnjah izobraževanja, med drugim na srednjih šolah in fakultetah. Nastala so torej za ocenjevanje pisanja $\mathrm{v}$ angleščini kot maternem jeziku, kar pojasnjuje nekatere njihove posebnosti. Ker se slovenski študentje in študentke angleščine kot tujega jezika na univerzitetnem nivoju izobražujejo za profesionalno rabo angleškega jezika, so spoznanja, do katerih pridemo z razčlembo meril Spandlove et al., dragocena in uporabna tudi za nas.

Kljub nekoliko samosvoji terminologiji in klasifikaciji (Misli in vsebina ${ }^{60}-$ Zakaj neki tudi misli - kaj niso misli tiste, ki tvorijo vsebino? Izbira besed ${ }^{61}$ za besedišče, Tekoča raba povedi ${ }^{62}$ za slog in Konvencije ${ }^{63}$ za pravopisni nadzor in jezikovno rabo/slovnico) v bistvu tudi navodila za ocenjevanje Spandlove et al. vsebujejo osnovne ocenjevane kategorije (vsebino, zgradbo, besedišče in slovnico); razen tega predvidevajo ločeno ocenjevanje sloga [po Spandel et al., kot smo videli, »tekoča raba povedi«] in osebne note ${ }^{64}$.

Posebnost obravnavanih navodil za ocenjevanje je tudi, da vsebujejo opisnike za tri ocenjevalne ravni: 5,3 in 1, čeprav naj bi uporabniki in uporabnice meril dodeljevali tudi 2 in 4 točke - torej dejansko ocenjevali na petih ravneh.

Bodite pozorni na to, da navodila za ocenjevanje vsebujejo določila (kriterije) na 5., 3. in 1. ocenjevalni ravni. 4. in 2. raven nista izrecno določeni (da navodila ne bi bila tako dolga, da jih ne bi nihče prebral). Od [ocenjevalcev in ocenjevalk] se pričakuje, da na ustrezen način sami oblikujejo razpon vseh ocenjevalnih ravni - 5., 4., 3., 2. in 1 .

Ocenjevalno raven 3 vzemite kot srednjo vrednost med močnimi in šibkimi platmi določenega vidika pisanja. Na 4. ocenjevalni ravni začnejo močne plati prevladovati nad šibkejšimi, medtem ko so na 5. ravni v večini. Podobno

59 Creating Writers: Linking Assessment and Writing Instruction

60 Ideas and Content

61 Word choice

62 Sentence fluency

63 Conventions

64 Voice 
velja za 2. ocenjevalno raven, na kateri pomanjkljivosti ocenjevanega vidika začnejo prevladovati nad močnimi platmi, medtem ko slednjih na 1. ocenjevalni ravni skoraj ni (čeprav ne smemo pozabiti, da izdelek lahko vsebuje močne plati, kar zadeva druge vidike pisanja). ${ }^{65}$

(Spandel in Stiggins 1990: 27-28)

Čeprav so citirana navodila razumljiva in smiselna, je utemeljitev, zakaj merila ne vsebujejo opisnikov za ravni 4 in 2, milo rečeno, nenavadna - da ne bi bila tako dolga, da jih ne bi nihče prebral? Si kot učitelji/ce smemo privoščiti takšen odnos?

Merila za vsako od treh ravni v vseh kategorijah vsebujejo splošen opis doseženega standarda za določeno raven, ki mu sledijo podrobnejši neodvisni opisniki, izraženi s celimi povedmi, ponekod z eno, drugod z dvema, tako da še ustrezajo kriteriju kratkosti.

Oglejmo si najprej opisnike za ocenjevanje vsebine, kjer opazimo tako koristne poudarke kakor tudi neustrezno kategorizirane in neprimerne opisnike. Splošen opis ravni, ki prinese 5 točk, pravi: »Izdelek je jasen, osredotočen in zanimiv. Zadrži bralčevo pozornost. Relevantne anekdote in podrobnosti obogatijo osrednjo temo ali pripoved. « ${ }^{66}$

Lastnosti »jasen«, »osredotočen« in »relevanten« so bolj povezane s koherenco, zato bi jih veljalo prestaviti v drugo kategorijo. Da je dobra vsebina zanimiva, se bomo bralci in bralke gotovo strinjali, problem je samo v tem, da se mnenje, kaj je zanimivo, od bralca do bralca razlikuje. Izbira med »osrednjo temo« in »pripovedjo« razkriva, da naj bi bili kriteriji uporabni tako za ocenjevanje razlagalnih kakor tudi pripovednih sestavkov (o čemur v spremljevalnem besedilu sicer ne preberemo niti besede). Navodilom za ocenjevanje v priročniku sledi vrsta po obravnavanih merilih ocenjenih in pokomentiranih vzorčnih sestavkov (namenjena urjenju v uporabi meril), ki to domnevo potrdi - poleg razlagalnih in pripovednih med njimi najdemo tudi opisne sestavke. Pomanjkljivost meril, ki naj bi pokrila tako širok razpon zvrsti, je v tem, da morajo ostati dovolj splošna, zato so manj uporabna za vsako posamezno zvrst. Druga možnost je, da vsebujejo opisnike, ki se nanašajo na eno in drugo zvrst; to pomeni, da je v določenih ocenjevalnih kontekstih del meril nerelevanten, kar je s stališča teorije testiranja sporno.

Prvi podrobnejši opisnik na 5. ocenjevalni ravni je prikrojen predvsem pripovednemu sestavku in se glasi: »Videti je, da pisanje temelji na osebni izkušnji pisca, ki izkazuje globlji vpogled: dober občutek za to, kako se dogodki razvijajo, kako se ljudje odzivajo na življenje in drug drugega in kako so misli med seboj povezane. $\ll^{67}$

$65 »$ Notice that the scoring guide presents definitions (criteria) for the various traits at the 5, 3, and 1 score levels. Levels 4 and 2 are not defined in writing (in order to keep the scoring guide from becoming so long that no one would read it), but you should assign the full range of scores $-5,4,3,2$, and 1 - as appropriate.

Think of a score of 3 as representing a balance between strong and weak with respect to a particular trait. At the 4 level, strengths begin to outweigh weaknesses, and at the 5 level, strengths are dominant. Similarly, at the 2 level, weaknesses begin to outweigh strengths, while at the 1 level, few if any strengths are evident with respect to the trait being scored (though, remember, there may be strengths in other traits). «

66 »This paper is clear, focused, and interesting. It holds the reader's attention. Relevant anecdotes and details enrich the central theme or story line.«

67 »The writer seems to be writing from experience and shows insight: a good sense of how events unfold, how people respond to life and each other, and how ideas relate.« 
Če pustimo ob strani, da sodi tudi način, »kako so misli med seboj povezane « h koherenci, se zdi neprimerno in sporno pričakovati, da bodo mladi pisci pisali na podlagi lastnih izkušenj, kljub temu, da so prav lastne izkušnje njihov najbogatejši in najbolj prepričljiv vir zamisli, kako utemeljiti svoje trditve (glej npr. Sokolov 2005: 233-235). Toda obstaja bistvena razlika med tem, da jim to omogočimo ali/in jih $\mathrm{k}$ temu spodbujamo, in tem, da to od njih pričakujemo celo do take mere, da vključevanje osebnih izkušenj postane del konstrukta/predmet ocenjevanja. Pisanje o lastnih izkušnjah za nameček tako in tako ni preverljivo in torej tudi ne merljivo - od tod modalni »videti je [da pisanje temelji na osebni izkušnji]«, ki nemara sugerira, da je »izkušnja« lahko izmišljena, vendar tako prepričljiva, da deluje, kot bi bila resnična. Kaj naj si pravzaprav pod tem »pričakovanjem« predstavljamo, je bolj razumljivo, ko si ogledamo še relevantne opisnike na srednji in najnižji ravni, kjer so nasproti mislim, ki jih pisec črpa iz lastnih izkušenj in razmišljanj, postavljene misli in opažanja, ki so označena kot »enolična « ${ }^{68}$, »že slišana ${ }^{69}$ na ravni 3

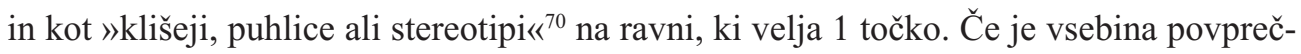
na/predvidljiva/»izrabljena«, kot ugotavljajo avtorji in avtorice meril (glede na to, da je Spandlova pri njihovem oblikovanju sodelovala $\mathrm{z}$ učitelji in učiteljicami), »bralec/bralka ne obžaluje, da se besedilo konča«. (Spandel in Stiggins 1990: 30) Po eni strani je tako po domače izražen opisnik zelo nazoren, po drugi pa vendar preveč prepuščen osebni presoji in okusu posameznega bralca/ocenjevalca oziroma bralke/ocenjevalke.

Naslednji opisnik na ravni 5 je bližje razlagalnemu in utemeljevalnemu sestavku: »Konkretne utemeljitve ter relevantne in zgovorne podrobnosti bralcu/bralki nudijo pomembne podatke, ki bi mu/ji bili sicer nedosegljivi. Videti je, da ta pisec opazi, kar bi drugi utegnili spregledati. $\ll^{71}$ Zadnji citirani stavek sicer na preprost in razumljiv način izrazi, kaj pomenijo »izvirni vpogledi«, a je hkrati sporno pričakovati, da bodo študentje in študentke za najvišjo oceno v svojih izdelkih navajali izključno podkrepitve, ki se jih bralec/bralka ne bi domislil/a sam/a, da o subjektivnosti presoje, katere podkrepitve bi sodile $\mathrm{v}$ to kategorijo in katere ne, niti ne izgubljam besed. Vprašljiv je tudi naslednji opisnik, ki izraža pričakovanje, da drugotne podkrepitve ne pritegnejo preveč pozornosti na račun prvotnih. Ker slednjim največkrat vdahnejo življenje prav prve (zanimive podrobnosti, primeri, anekdote), ni razloga, da se v bralčev/bralkin spomin ne bi smele vtisniti bolj kot glavne misli - katerih sporočilna moč se posredno okrepi prav s pomočjo drugotnih podkrepitev.

Merila v nadaljevanju poudarjajo pomen razvoja teme »na informativen in zabaven način $\ll^{72}$, kjer smo spet soočeni s težavo, kako interpretirati zlasti pridevnik »zabaven«.

\footnotetext{
68 »mundane«

69 »heard elsewhere«

70 "clichés, platitudes, or stereotypes«

71 »Supporting, relevant, telling details give the reader important information that he or she could not personally bring to the text. This writer seems to notice what others might overlook.«

72 »in an enlightening, entertaining way«
} 
Zadnji opisnik pod »Misli in vsebina« poudarja pomen razmišljanja z lastno glavo, če naj si kandidat prisluži najvišjo oceno: »Pisec uporablja in oblikuje misli, pri čemer ustvarja povezave in z bralci deli vpoglede, ki odražajo njegovo lastno mišljenje." 73 Tudi presoja kritičnega mišljenja je vsaj delno subjektivna.

Po pričakovanjih je z drugimi opisniki, katerih razumevanje je manj odvisno od subjektivnosti ocenjevalca/ocenjevalke, manj težav. Tako se z izjemo opisnikov »privlačen uvod $\aleph^{74}$ in »zadovoljiv zaključek $\aleph^{75}$, ki bi bolj sodila k vsebini, vsi opisniki v kategoriji zgradba nedvoumno navezujejo na koherenco besedila. Posebej koristen se zdi zadnji, ki ubesedi občutek, ki ga ustvari zares koherentno besedilo: "Zgradba omogoča tako tekoče branje, tako da se bralec nemara niti ne zaveda njenih sestavnih delov, razen če jim zavestno posveti pozornost. ${ }^{76}$ Tudi naslednji opisnik je s svojo neposrednostjo nadvse dobrodošel: »Razporeditev ali nerelevantnost nekaterih podrobnosti bralca/bralko občasno zmede ali ga/jo vznejevolji.«" ${ }^{77}$ Skratka - opisniki, ki se nanašajo na logično zgradbo in koherenco besedila, so večinoma ne samo primerni, ampak zaradi podrobne, nazorne in življenjske obravnave hkrati presegajo večino opisnikov iz drugih meril, navedenih v strokovni literaturi. Poleg v tem odstavku uvodoma omenjene neustrezne kategorizacije, me zmoti samo še napačna terminologija v naslednjem opisniku: »Povezovalci so uporabljeni tekoče in stkejo posamezne pomenske niti v kohezivno celoto. ${ }^{78} \mathrm{Na}$ mestu termina »kohezivno« bi moral biti izraz »koherentno«.

Pri naslednji kategoriji je objektivnost interpretacije meril spet otežena - ocenjevanje osebne note, sicer pomembne sestavine učinkovitega pisanja, je še bolj subjektivno kot ocenjevanje vsebine, kar je razvidno iz večine opisnikov. Oglejmo si niz nazornih zgledov. Raven 5: »Izdelek je iskren in napisan od srca. Zveni prepričljivo. «" $/ »$ Bralec/ Bralka občuti močno interakcijo s piscem besedila in za besedami zaznava človeka. ${ }^{80}$ / »Ton in osebna nota (...) začinita avtorjevo/avtoričino sporočilo. $«^{81}$ Raven 3: »Videti je, da avtor/ica skrbno pretehtava besede, da bi med seboj in bralcem obdržal/a varno razdaljo, da bi se izognil/a tveganju in da bi pisal/a o tistem, za kar meni, da bralec/bralka pričakuje. $\ll^{82} /$ »Pisanje izkazuje piščevo težnjo k skrivanju namesto k razkrivanju ${ }^{83}$.

73 »The writer works with and shapes ideas, making connections and sharing insights that reflect his or her own thinking. «

74 »an inviting introduction«

75 »a satisfying conclusion«

76 »Organization flows so smoothly that the reader may not be conscious of organizational patterns or structures unless looking for them.«

77 »Placement or irrelevance of some details leaves the reader occasionally confused or impatient.«

78 »Transitions are smooth and weave the separate threads of meaning into one cohesive whole.«

79 »The paper is honest and written from the heart. It has a ring of conviction.«

80 »The reader feels a strong sense of interaction with the writer and senses the person behind the words.«

81 »The projected tone and voice (...) give flavor to the writer's message.«

82 »The writer seems to weigh words carefully, to keep a safe distance between writer and reader, to avoid risk, and to write what he or she thinks the reader wants.«

83 »The writing tends to hide rather than reveal the writer.« 
/ „Osebna nota je lahko na trenutke močno prisotna, a že čez eno ali dve vrstici preskoči ali izgine za fasado splošnega, neizrazitega ali abstraktnega jezika. $\ll^{84}$ Raven 1 : »Bralec/Bralka ne zaznava pisca za besedami in nima občutka, da si pisec zares želi karkoli sporočiti. ${ }^{85} / »$ Videti je, da avtor piše monotono, kar izniči učinek potencialno izstopajočih misli in delov sporočila, ki naj bi ostali v ozadju. « ${ }^{86} /$ /Pisanje v najboljšem primeru sporoča na funkcionalni ravni, vendar se bralca/bralke ne dotakne oziroma ga/je ne vključi v interakcijo z besedilom. $«{ }^{87}$ Visoka stopnja modalnosti v opisnikih (»zveni«, »(ne) zaznava človeka za besedami«, »videti je«, »izkazuje težnjo k«) že sama po sebi izpostavlja negotovo naravo/nedorečenost vrednotenja osebne note $\mathrm{v}$ besedilih. Težko je presoditi, ali se je konkreten študent/konkretna študentka za določen način pisanja odločil/a zato, da bi ustregel/ustregla učiteljici/bralki. In kako vedeti, ali se je premalo potrudil/a, da bi se z bralcem/bralko zares povezal/a, mu/ji sporočil/a kaj pomembnega? Zelo kočljivo je tudi pričakovanje, da se bo avtor/ica besedila razkril/a. Ne glede na resne pomisleke, ki se odražajo tudi $\mathrm{v}$ dejstvu, da večina drugih meril za ocenjevanje tega vidika pisanja ne vsebuje, vsaj ne v samostojni kategoriji, menim, da je posvečanje pozornosti osebni noti pri pisanju izredno pomembno in vznemirljivo.

V kategoriji besedišče je interpretacija opisnikov spet bolj oprijemljiva. Med njimi so sicer tudi taki, ki vsebujejo modalnost in (z njo povezano in siceršnjo) nedorečenost, $\mathrm{s}$ tem pa tudi nedoločenost, kot recimo v opisniku »Besede se zdijo ravno pravšnje « ${ }^{88}(\mathrm{kar}$ koli že to pomeni) ali »V izdelku je lahko nekaj dobrih rešitev $\ll^{89}$ (poudarek avtorjev) in »Bralcu/Bralki se za razumevanje ni treba naprezati $\ll^{90}$, medtem ko praviloma prevladuje natančnost. Dobrodošli so zlasti opisniki, ki pokrivajo, kar srečujem pri svojem delu (ocenjevanju izdelkov študentov in študentk), ne pa tudi v številnih merilih iz strokovne literature, na primer: »Besedišče nemara v ničemer ne izstopa, vendar je naravno in nikoli pretirano. $\ll^{91} / » P i s e c$ uporablja sveže besedišče in le izjemoma sleng $«^{92}$. / $/$ Čeprav je na splošno pomen jasen, delu besedišča manjka natančnost. $\aleph^{93} /$ »Poskusi vključevanja barvitega in poetičnega jezika pogosto delujejo pretirano in preračunljivo, kot da bi pisec želel narediti vtis na bralca. $\ll^{94}$ (Previdnost pri ocenjevanju, ali so študentje in

$84 »$ Voice may emerge strongly on occasion, only to shift or to disappear a line or two later behind a facade of general, vague, or abstract language. «

85 »The reader has no sense of the writer behind the words and no sense of a real desire on the part of the writer to communicate."

86 »The writers seems to speak in a kind of monotone that flattens all potential highs or lows of the message."

87 »The writing communicates on a functional level, at best, without moving or involving the reader at all«.

88 »[Words] seem just right."

89 »The paper may have some fine moments.«

90 »There is little for the reader to grasp."

91 »Vocabulary may not be striking, but it's natural and never overdone.«

92 "Expression is fresh and appealing; slang is used sparingly."

93 »While the overall meaning is clear, some words may lack precision.«

94 »Attempts at colorful or poetic language often seem to be overdone and calculated to impress the reader.« 
študentke »preračunljivi«!) / »Klišeji, odvečne besede in izrabljene fraze so pogoste. $\aleph^{95}$ / »Besedilo 'naseljuje' zgolj splošno besedišče. «96 / »Glagoli so šibki in maloševilni; prevladujejo je, so, je bil, so bili. «97 Menim, da bi številna merila pridobila, če bi si izposodila katerega od navedenih opisnikov. Na koncu ne bo odveč opozorilo, da merila Spandlove et al. predvidevajo napake v rabi besedišča šele na najnižji (in, predvidoma, tudi na nespecificirani drugi najnižji) ravni, medtem ko se napake dejansko pojavijo tudi na višjih ravneh - najbrž moramo spodrsljaj ali dva tolerirati celo na najvišji ravni (tudi pri domačih govorcih).

Pri slogu (kategorija Tekoča raba povedi) so napake, razumljivo, prvič prav tako omenjene šele na najnižji ravni, sicer pa se opisniki večinoma nanašajo na »tok in ritem pisanja $\ll^{98}$, poudarjajo vlogo jezikovnih struktur pri logičnem povezovanju misli (kar pomeni, da so razvrščeni v neustrezno kategorijo) in pomen rabe raznolikih jezikovnih konstrukcij (»Povedi se razlikujejo po zgradbi in dolžini, kar prispeva k zanimivosti besedila $\ll^{99}$ ) Z nekaterimi opisniki gredo sestavljalci/sestavljalke v svojih pričakovanjih in subjektivnosti predaleč, kot recimo pri opisniku »V besedilu se učinkovito prepletajo močne in lahkotne povedi. « ${ }^{100}$

Kot smo že zapisali, Spandlova et al. h konvencijam (jezikovne rabe) prištevajo tako slovnično pravilnost kakor tudi pravopis in členitev besedila v odstavke. Obravnavo slovnice in pravopisa v skupni kategoriji odobravam, zakaj členitev v odstavke po moji presoji vanjo ne sodi, pa sem že pojasnila. Prav je, da smejo v tej kategoriji tudi najboljši narediti kakšno napako (»Tudi težje besede so na splošno zapisane pravilno.«101 - moj poudarek), po drugi strani pa v njej opažam primere neustrezne kategorizacije, na primer »Lahko se zgodi, da pisec z namenom, da bi dosegel slogovni učinek, krši konvencije - predvsem slovnične. «102. Takšno ponavljanje 'vsebin' ocenjevalce/ocenjevalke spodbuja $\mathrm{k}$ vrednotenju sloga $\mathrm{v}$ dveh kategorijah (pod Tekoča raba povedi in Konvencije). Tudi glede opisnika »Potrebni bi bili zgolj manjši lektorski popravki, če bi želeli besedilo izpiliti za objavo. $\aleph^{103}$ lahko pričakujemo različne poglede - je za najvišje število točk dovolj dobro res zgolj besedilo, ki je (skoraj) primerno za objavo? Poleg tega je tudi pri tem opisniku problematična subjektivnost presoje.

Kot je razvidno iz analize navodil za ocenjevanje, pomislekov glede njihove primernosti v konkretnih primerih ne manjka. Kljub temu predstavljajo izjemen prispevek k razčlenjevalnemu ocenjevanju pisnih sestavkov, zlasti zato, ker so tako drugačna od večine

\footnotetext{
95 »Clichés, redundancies, and hackneyed phrases are common.«

96 »The text is 'peopled' only with generalities.«

97 »Verbs are weak and few in number; is, are, was, were dominate.«

98 »flow and rhythm of writing«

99 »Sentences vary in structure and length, adding interest to the text.«

100 »Sentences display an effective combination of power and grace.«

101 »Spelling is generally correct, even more difficult words.«

102 »The writer may manipulate conventions - particularly grammar - for stylistic effect.«

103 »Only light editing would be required to polish the text for publication.«
} 
drugih meril - podrobnejša (ne glede na to, da pokrijejo samo tri ravni, preostali dve pa si moramo 'zamisliti' sami), manj 'teoretična', s tem pa uporabnikom/uporabnicam prijaznejša, in drznejša (ker posegajo na področji, ki ju ostali teoretiki ocenjevanja pisne zmožnosti zgolj mimogrede oplazijo ali se jima v celoti izognejo - na področji sloga in osebne note). Zaradi vsega tega bi bilo zaželeno, da bi se kdo lotil odpravljanja njihovih pomanjkljivosti in jih sčasoma izpilil do različice, v kateri bi prevladovale njihove prednosti.

\section{6}

\section{SKLEPNE MISLI}

V presoji, katere prvine pisanja so tako pomembne, da naj postanejo del konstrukta, so si strokovnjaki in praktiki testiranja dokaj enotni (glej tudi Sokolov 2014). Kot posebnost izstopata ocenjevanje osebne note in sloga v merilih Spandlove in Stigginsa, pri čemer je treba poudariti, da je oboje z uvedbo ustreznih opisnikov mogoče ocenjevati tudi znotraj osnovnih kategorij (osebno noto denimo znotraj vsebine in slog tako v okviru zgradbe kakor tudi besedišča in jezikovne rabe). Pri vseh ostalih razlikah se ob natančnejšem pregledu opisnikov izkaže, da gre bolj za razlike pri poimenovanju ocenjevanih vidikov in pri kategorizaciji opisnikov kot za omembe vredna razhajanja. Tudi neenakomerna obtežitev kategorij v merilih Jacobs et al. v resnici odstopa samo na prvi pogled: ker gre pri pravopisnem nadzoru v bistvu za del jezikovne rabe, lahko točke zanj prištejemo $\mathrm{k}$ slednji; s tem postane največje možno število točk za jezikovno pravilnost enako številu točk za vsebino (30 točk). Razlika med vrednotenjem vsebine in zgradbe ni majhna (10 točk v prid vsebini), kar velja tudi za razliko med vrednotenjem jezikovne pravilnosti in besedišča. Toda če upoštevamo tesno prepletenost vsebine in koherence (ki skupaj veljata 50 točk) in dejstvo, da sta tako besedišče kot slovnica (ki prav tako prineseta do 50 točk) del jezika, ugotovimo, da so vidiki pisnega izdelka pravzaprav tudi v merilih Jacobs et al. obravnavani dokaj uravnoteženo. 


\begin{tabular}{|c|c|c|c|c|c|c|c|}
\hline \multirow[b]{2}{*}{ MERILA } & \multicolumn{7}{|c|}{ OCENJEVANE KATEGORIJE } \\
\hline & vsebina & $\begin{array}{c}\text { zgradba/ } \\
\text { koh. }\end{array}$ & besedišče & $\begin{array}{l}\text { Jezik. } \\
\text { raba }\end{array}$ & $\begin{array}{l}\text { Konven- } \\
\text { cije }\end{array}$ & glas & slog \\
\hline $\begin{array}{l}\text { Jacobs et al } \\
\text { (1981) }\end{array}$ & $\begin{array}{c}13 \text { do } 30 \\
\text { točk }\end{array}$ & $\begin{array}{c}7 \text { do } 20 \\
\text { točk }\end{array}$ & $\begin{array}{c}7 \text { do } 20 \\
\text { točk }\end{array}$ & $\begin{array}{l}5 \text { do } 25 \\
\text { točk }\end{array}$ & $\begin{array}{l}\text { (Pravo- } \\
\text { pis) } \\
2 \text { do } 5 \\
\text { točk }\end{array}$ & & \\
\hline $\begin{array}{l}\text { Spandel in } \\
\text { Stiggins } \\
(1990)\end{array}$ & $\begin{array}{c} \\
\text { (Misli in } \\
\text { vsebina) } \\
1 \text { do } 5 \\
\text { točk }\end{array}$ & $\begin{array}{c}V \\
\text { (Zgradba) } \\
1 \text { do } 5 \\
\text { točk }\end{array}$ & $\begin{array}{c}V \\
\text { (Izbira } \\
\text { besed) } \\
1 \text { do } 5 \\
\text { točk }\end{array}$ & $\begin{array}{c}V \\
\text { (Kon- } \\
\text { vencije) } \\
1 \text { do } 5 \\
\text { točk }\end{array}$ & $\begin{array}{c}\checkmark \\
\text { (Konven- } \\
\text { cije) } \\
1 \text { do } \\
5 \text { točk }\end{array}$ & $\begin{array}{c}V \\
\text { (Osebna } \\
\text { nota) } \\
1 \text { do } 5 \\
\text { točk }\end{array}$ & $\begin{array}{c}\vee \\
\text { (Tekoča } \\
\text { raba } \\
\text { povedi) } \\
1 \text { do } 5 \text { točk }\end{array}$ \\
\hline
\end{tabular}

Preglednica: Primerjava ocenjevanih kategorij in njihove teže v obravnavanih merilih

Kar merilom najbolj manjka, sta poenotena terminologija in kategorizacija opisnikov (prim. Sokolov 2014). Trenutna raznolikost nemara do neke mere razkriva raziskovalni duh, po drugi strani pa morda tudi samovoljnost, samozadostnost in, deloma, pomanjkljivo teoretično podkovanost strokovnjakov in strokovnjakinj za testiranje, ki se ne potrudijo dovolj, da bi raziskali, kaj je na tem področju že dognanega, kategoriziranega in/ali poimenovanega. Teoretikom v opravičilo naj hkrati omenim izmuzljivo naravo zapletenega procesa pisanja (ki se za nameček razlikuje od pisca do pisca). Različni pogledi na to, kateri podvidik pisanja sodi v to ali ono kategorijo, so zato razumljivi. Pomembno je, da o njih razmišljamo, diskutiramo in premoščamo različne interpretacije. Upoštevati velja tudi stališče, naj bodo pristopi k testiranju prožni in prilagojeni konkretnemu kontekstu, ki ga zavzeto, čeprav teoretično skromno utemeljeno, zastopata denimo Spandel in Stiggings (1990: 149).

Vsekakor bi bilo dobrodošlo, da bi v prihodnosti kdo od raziskovalcev/raziskovalk na tem področju naredil nekaj več reda. V primerih, ko se ena in ista pomanjkljivost pojavlja v različnih merilih, bi lahko denimo prispeval/a k razumevanju, zakaj je tako, in $\mathrm{k}$ iskanju ustreznejših rešitev. Pri razmejevanju kategorij vsebine in koherence, na primer, velja (zlasti glede na njuno tesno prepletenost) razmisliti, ali ne bi bilo smiselno obeh kategorij združiti v eno. Po drugi strani pa lahko raznolikost meril učitelji/ce obrnemo sebi (in učencem/učenkam) v prid tako, da iz različnih virov izberemo tisto, kar najbolj ustreza našemu izobraževalnemu kontekstu in našim strokovnim premislekom. Namen tega članka tako ni končna sodba, katera od obeh zgledov obravnavanih meril so boljša, temveč spodbuda k iskanju lastnih poti ob podpori gradiv, ki so jih že domislili drugi. 


\section{BIBLIOGRAFIJA}

BACHA, Nahla (2001) Writing evaluation: what can analytic versus holistic essay scoring tell us? System 29: 371-383.

BROWN, H. Douglas (2004) Language Assessment: Principles and Classroom Practices. New York: Longman.

CARR, Nathan T (2000) A Comparison of the Effects of Analytic and Holistic Rating Scale Types in the Context of Composition Tests. Issues in Applied Linguistics 11 (2): 207-241.

COUNCIL OF EUROPE (2001) Common European Framework of Reference for Languages: Learning, Teaching, Assessment. Cambridge: Cambridge University Press.

CUSHING WEIGLE, Sara (2002) Assessing Writing. Cambridge: Cambridge University Press.

ČOKL, Sonja in Gašper CANKAR (2008) Raziskava različnih vrst kriterijev za ocenjevanje maturitetnih esejev iz slovenščine. Ljubljana: Državni izpitni center.

(2009) English Writing: Writing Mechanics. Athens, Ohio: Ohio University, Department of Linguistics. 29. november 2012. http://www.ohio.edu/linguistics/esl/writing/mechanics.html.

ENKVIST, Nils Erik (1990) Seven Problems in the Study of Coherence and Interpretability. Ulla Connor in Ann M. Johns (ur.), Coherence in Writing: Research and Pedagogical Perspectives. Alexandria: TESOL, 11-28.

HAMP-LYONS, Liz (1990) Second language writing: assessment issues. Barbara Kroll (ur.), Second Language Writing: Research insights for the classroom. Cambridge: Cambridge University Press, 69-87.

HARRIS, David Payne (1969) Testing English as a Second Language. New York: McGraw-Hill Book Company.

HASWELL, Richard H. (2002/2007) Researching Teacher Evaluation of Second Language Writing via Prototype Theory. Paul Kei Matsuda in Tony Silva (ur.) (2005) Second Language Writing Research: Perspectives on the Process of Knowledge Construction. Erlbaum, 105-120. 26. april 2018. http://www.writing.ucsb.edu/wrconf08/Pdf_Articles/Haswell-Article.pdf.

HUGHES, Arthur (1989/2003) Testing for Language Teachers. (2. izd.) Cambridge: Cambridge University Press.

JACOBS, Holly J., Stephen A. ZINKGRAF in Deanna R. WORMUTH (1981) ESL Composition Profile. Faye Hartfiel in Jane B. Hughey (ur.), Testing ESL composition: a practical approach. Rowley, Mass: Newbury House.

LANG, Margaret (1995) Coherence and Cohesion. Izroček ob predavanju »The need for mother tongue competence and the need to teach transferable skills in translation and interpreting «. (2. sestanek projekta TEMPUS, 14.10.1995). Ljubljana: Filozofska fakulteta UL. 
McCARTHY, Michael (1991) Discourse Analysis for Language Teachers. Cambridge: Cambridge University Press.

POLIO, Charlene (2001) Research Methodology in Second Language Writing Research: The Case of Text-Based Studies. Tony Silva in Paul Kei Matsuda (ur.), On Second Language Writing. Mahwah, New Jersey in London: Lawrence Erlbaum Associates, 91-115.

Sample Assessment Rubrics (SAR): Speaking and Writing Rubric (2018) (Tiptiktak). 18. julij 2018. https://tiptiktak.com/speaking-and-writing-rubric.html.

SCHOONEN, Rob, Patrik SNELLINGS, Marie STEVENSON in Amos van GELDEREN. (2009) Towards a Blueprint of the Foreign Language Writer: The Linguistic and Cognitive Demands of Foreign Language Writing. Rosa M. Manchón (ur.). Writing in Foreign Language Contexts: Learning, Teaching, and Research. Bristol: Multilingual Matters, 77-101.

SOKOLOV, Cvetka (1999) Pisni sestavek pri študentih angleščine. (Neobjavljeno magistrsko delo). Ljubljana: Filozofska fakulteta UL, Oddelek za anglistiko in amerikanistiko.

SOKOLOV, Cvetka (2013) Pomen standardizacije ocenjevanja pisnih sestavkov pri poučevanju angleščine kot tujega jezika. (Neobjavljena doktorska disertacija). Ljubljana: Filozofska fakulteta UL, Oddelek za anglistiko in amerikanistiko.

SOKOLOV, Cvetka (2014) Merila za ocenjevanje pisnih sestavkov. (Neobjavljena, modificirana v lektorski skupini Oddelka za anglistiko in amerikanistiko FF; sprejeta v uporabo v 2014/15.) Ljubljana: Filozofska fakulteta UL.

SPANDEL, Vicki in Richard J. STIGGINS (1990) Creating Writers: Linking Assessment and Writing Instruction. New York in London: Longman.

WIDDOWSON, Henry (1984) The realization of rules in written discourse. (Explorations in Applied Linguistics.) Oxford: Oxford University Press.

WIKBORG, Eleanor (1990) Types of Coherence Breaks in Swedish Student Writing: Misleading Paragraph Division. Ulla Connor in Ann M. Johns (ur.), Coherence in Writing: Research and Pedagogical Perspectives. Alexandria: TESOL, 133-148.

\section{POVZETEK}

V članku avtorica analizira in ovrednoti dva zgleda razčlenjevalnih meril za ocenjevanje razlagalnih/utemeljevalnih sestavkov, in sicer Meril Holly L. Jacobs et al. (1981) in Navodil za ocenjevanje Vicki Spandlove et al. (1990). Avtorica prispevka je obravnavana merila izbrala zato, ker so med učitelji in učiteljicami še vedno zelo priljubljena. Pri pretresanju dobrih in slabih plati meril se osredotoča na lastnosti opisnikov. V skladu s priporočili Splošnega evropskega jezikovnega okvira/SEJO (2001: 205-207) ugotavlja, do kakšne mere so dorečeni, jasni, kratki in neodvisni. Analiza razkriva, koliko sta si zgleda meril podobna in v čem se razlikujeta, obravnava njune dobre 
in šibke plati in pripelje do zaključka, da bi učitelji in učiteljice morali navodila za ocenjevanje kritično ovrednotiti, po potrebi izboljšati in prilagoditi izobraževalnemu kontekstu, v katerem delujejo, preden jih začnejo uporabljati.

Ključne besede: merila za ocenjevanje pisne zmožnosti, navodila za ocenjevanje, lastnosti opisnikov, Splošni evropski jezikovni okvir, izobraževalni kontekst

\section{ABSTRACT}

\section{An analysis of two sets of analytical expository and argumentative writing assessment criteria}

The article focuses on the analysis of two sets of analytical writing assessment criteria, namely the scoring guides by Meril Holly L. Jacobs et al. (1981) and by Vicki Spandl et al. (1990), evaluating them in terms of their descriptors' features. Writing assessment descriptors should be definite, clear, brief and independent as recommended by the Common European Framework of Reference for Languages (2001: 205-207). Both scoring guides were chosen because they are still used by teachers extensively. The analysis displays similarities and differences between the two scoring guides, their strengths and weaknesses, and the need for teachers to evaluate a particular scoring guide critically before starting to use it, to introduce improvements if necessary and, finally, to adjust the writing assessment criteria to their educational context.

Key words: writing assessment criteria, scoring guides, descriptors' features, Common European Framework of Reference for Languages, educational context 